\title{
Medial Gamma Knife thalamotomy for intractable pain
}

\author{
Dusan Urgosik, MD, PhD, and Roman Liscak, MD, PhD \\ Department of Stereotactic and Radiation Neurosurgery, Na Homolce Hospital, Prague, Czech Republic
}

OBJECTIVE Ablative procedures are still useful in the treatment of intractable pain despite the proliferation of neuromodulation techniques. In the paper the authors present the results of Gamma Knife thalamotomy (GKT) in various pain syndromes.

METHODS Between 1996 and 2016, unilateral GKT was performed in 30 patients suffering from various severe pain syndromes in whom conservative treatment had failed. There were 20 women and 10 men in the study population, with a median age of 80 years (range 53-89 years). The pain syndromes consisted of 8 patients with classic treatmentresistant trigeminal neuralgia (TN), 6 with postherpetic TN, 5 with TN and constant pain, 1 with TN related to multiple sclerosis, 3 with trigeminal neuropathic pain, 4 with thalamic pain, 1 with phantom pain, 1 with causalgic pain, and 1 with facial pain. The median follow-up period was 24 months (range 12-180 months). Invasive procedures for pain release preceded GKT in 20 patients (microvascular decompression, glycerol rhizotomy, balloon microcompression, Gamma Knife irradiation of the trigeminal root, and radiofrequency thermolesion). The Leksell stereotactic frame, GammaPlan software, and T1- and T2-weighted sequences acquired at 1.5 T were used for localization of the targeted medial thalamus, namely the centromedian (CM) and parafascicularis (Pf) nucleus. The CM/Pf complex was localized 4-6 mm lateral to the wall of the third ventricle, $8 \mathrm{~mm}$ posterior to the midpoint, and 2-3 $\mathrm{mm}$ superior to the intercommissural line. GKT was performed using the Leksell Gamma Knife with an applied dose ranging from 145 to $150 \mathrm{~Gy}$, with a single shot, 4-mm collimator. Pain relief after radiation treatment was evaluated. Decreased pain intensity to less than $50 \%$ of the previous level was considered successful.

RESULTS Initial successful results were achieved in $13(43.3 \%)$ of the patients, with complete pain relief in 1 of these patients. Relief was achieved after a median latency of 3 months (range 2-12 months). Pain recurred in 4 (31\%) of 13 patients after a median latent interval of 24 months (range 22-30 months). No neurological deficits were observed.

CONCLUSIONS These results suggest that GKT in patients suffering from severe pain syndromes is a relatively successful and safe method that can be used even in severely affected patients. The only risk of GT for the patients in this study was failure of treatment, as no clinical side effects were observed.

https://thejns.org/doi/abs/10.3171/2018.7.GKS181583

KEYWORDS medial thalamotomy; Gamma Knife; stereotactic radiosurgery; intractable pain

$\mathrm{T}$ HE treatment of pain, especially of benign origin, is often arduous, and in the last several years has fallen primarily under the domain of neuromodulatory techniques, including pharmacological and electrostimulatory techniques. Both cortical stimulation and deep brain stimulation in structures that produce paresthesia (e.g., the thalamus and medial lemniscus), ${ }^{4}$ as well as nonparesthetic structures (such as the periaqueductal gray matter), ${ }^{16}$ offer a more or less successful and reversible neurosurgical method of pain relief. A similar trend can be seen in other areas of functional neurosurgery, namely movement disorders, psychiatric disorders, and epilepsy. Choosing an ablative procedure to treat functional disorders has become somewhat looked down upon by some professional groups. Nevertheless, there has been a renaissance in lesional interventions in recent years, ${ }^{1,8,10}$ including the use

ABBREVIATIONS BNI = Barrow Neurological Institute; $C L p=$ posterior part of the centrolateral thalamic nucleus; $C M=$ centromedian; GKS = Gamma Knife surgery; GKT = Gamma Knife thalamotomy; MVD = microvascular decompression; Pf = parafascicularis; tcMRgFUS = transcranial magnetic resonance imaging-guided focused ultrasound; TDP = trigeminal deafferentation pain; TN = trigeminal neuralgia; TN1 = TN originally classified as classic neuralgia; TN2 = TN with mixed constant and episodic pain and burning; TNP = trigeminal neuropathic pain.

SUBMITTED June 2, 2018. ACCEPTED July 31, 2018.

INCLUDE WHEN CITING DOI: 10.3171/2018.7.GKS181583. 
TABLE 1. Patient characteristics and results of GKT

\begin{tabular}{|c|c|c|c|c|c|c|c|c|}
\hline $\begin{array}{l}\text { Case } \\
\text { No. }\end{array}$ & $\begin{array}{l}\text { Age (yrs), } \\
\text { Sex }\end{array}$ & Diagnosis & Previous Surgery & $\begin{array}{l}\text { Max Dose } \\
\text { (Gy) }\end{array}$ & $\begin{array}{l}\text { Pain Relief } \\
(\%)\end{array}$ & $\begin{array}{c}\text { BNI } \\
\text { Score }\end{array}$ & $\begin{array}{l}\text { Onset of Pain Relief } \\
\text { (mos) }\end{array}$ & $\begin{array}{l}\text { Recurrence } \\
\text { (mos) }\end{array}$ \\
\hline 1 & $71, \mathrm{~F}$ & TP & - & 150 & 100 & 5 & - & - \\
\hline 2 & $56, \mathrm{~F}$ & TP & - & 150 & 60 & 4 & 3 & - \\
\hline 3 & $66, \mathrm{M}$ & TP & - & 150 & 100 & 5 & - & - \\
\hline 4 & $54, \mathrm{M}$ & TP & - & 145 & 100 & 5 & - & - \\
\hline 5 & $66, \mathrm{~F}$ & TN1 to TDP & Glycerol rhizotomy & 150 & 50 & 3 & 6 & 30 \\
\hline 6 & $53, \mathrm{~F}$ & TN1 to TDP & LGN & 150 & 100 & 5 & - & - \\
\hline 7 & $86, F$ & TN1 to TDP & LGN, BC & 150 & 0 & 1 & 2 & - \\
\hline 8 & $78, \mathrm{M}$ & TN1 to TDP & LGN & 145 & 50 & 3 & 6 & - \\
\hline 9 & $80, F$ & TN1 to TDP & LGN & 150 & 30 & 3 & 12 & 24 \\
\hline 10 & $89, \mathrm{M}$ & TN1 to TDP & TL, LGN & 145 & 70 & 4 & 6 & - \\
\hline 11 & $55, \mathrm{M}$ & msTN & BC, LGN & 150 & 50 & 3 & 3 & 22 \\
\hline 12 & $70, \mathrm{~F}$ & TN1 to TDP & LGN & 145 & 50 , followed by drop to 5 & 2 & $\begin{array}{c}3 \text { (1st alleviation), then } 7 \\
\text { (2nd alleviation) }\end{array}$ & - \\
\hline 13 & $70, \mathrm{~F}$ & TN1 to TDP & LGN & 145 & 100 & 5 & - & - \\
\hline 14 & $80, \mathrm{M}$ & TN2 & LGN, BC & 145 & 100 & 5 & - & - \\
\hline 15 & $64, F$ & TN2 & MVD, LGN & 145 & 100 & 5 & - & - \\
\hline 16 & $73, \mathrm{~F}$ & TN2 & LGN & 145 & 100 & 5 & - & - \\
\hline 17 & $68, M$ & TN2 & - & 145 & 100 & 5 & - & - \\
\hline 18 & $67, \mathrm{~F}$ & TN2 & - & 145 & 30 & 3 & 3 & - \\
\hline 19 & $70, \mathrm{~F}$ & PHN & LGN & 150 & 30 & 3 & 3 & - \\
\hline 20 & $73, \mathrm{~F}$ & $\mathrm{PHN}$ & LGN & 150 & 100 & 5 & - & - \\
\hline 21 & $66, \mathrm{~F}$ & $\mathrm{PHN}$ & - & 150 & 100 & 5 & - & - \\
\hline 22 & $82, F$ & $\mathrm{PHN}$ & LGN & 150 & 40 & 3 & - & - \\
\hline 23 & $56, F$ & $\mathrm{PHN}$ & - & 150 & 100 & 5 & - & - \\
\hline 24 & $66, F$ & $\mathrm{PHN}$ & LGN & 145 & 50 & 3 & 4 & - \\
\hline 25 & $54, F$ & TNP & LGN & 150 & 100 & 5 & & - \\
\hline 26 & $64, \mathrm{M}$ & TNP & LGN & 145 & 50 & 3 & 4 & - \\
\hline 27 & $61, F$ & TNP & CM thermolesion & 145 & 60 , followed by a drop to 50 & 3 & $\begin{array}{c}2 \text { (1st alleviation), then } 8 \\
\text { (2nd alleviation) }\end{array}$ & - \\
\hline 28 & $54, \mathrm{~F}$ & $\mathrm{CP}$ & - & 150 & 100 & 5 & - & - \\
\hline 29 & $54, \mathrm{M}$ & $\mathrm{PhP}$ & - & 150 & 10 & 2 & 4 & 22 \\
\hline 30 & $60, M$ & $\mathrm{FP}$ & - & 145 & 100 & 5 & - & - \\
\hline
\end{tabular}

$\mathrm{BC}=$ balloon compression in Meckel's cave; $\mathrm{CP}=$ causalgic pain; FP = facial pain of unknown origin; LGN = irradiation of the root of the trigeminal nerve; msTN = TN related to multiple sclerosis; $\mathrm{PHN}=$ postherpetic $\mathrm{TN} ; \mathrm{PhP}=$ phantom pain; $\mathrm{TDP}=$ trigeminal deafferentation pain; $\mathrm{TL}=$ retrogasserian thermolesion; $\mathrm{TP}=$ thalamic pain .

of Gamma Knife surgery (GKS) for the treatment of various functional disorders. ${ }^{11,15}$ The treatment of functional disorders by GKS is actually a partial return to the root of this method. ${ }^{11,15}$ Functional radiosurgical procedures ${ }^{13,17}$ in the thalamus were developed based on the hypothesis of the medial thalamic center's role in the physiopathology of pain..$^{5}$ This theory was later confirmed by the results of stereotactic medial thalamotomy., ${ }^{3,6,12}$ Encouraged by recent GKS results in patients with tremor ${ }^{11,15}$ and the results of transcranial magnetic resonance imaging-guided focused ultrasound (tcMRgFUS) thalamotomy in patients with intractable pain published recently, ${ }^{8,10}$ we retrospectively evaluated the outcomes of patients who suffered from intractable pain and were treated by Gamma Knife thalamotomy (GKT) at our center over the past 20 years.

\section{Methods}

\section{Study Population}

Between 1996 and 2016, 30 patients suffering from severe pain syndromes of various etiologies underwent medial thalamotomy using GKS. There were 20 women and 10 men, with a median age of 80 years (range 53-89 years; Table 1). In all patients, pharmacological and/or neurosurgical treatment had failed prior to GKS. The median duration of pain was 84 months (range 12-300 months) and the median follow-up duration was 24 months (range 12-180 months); some patients were lost to follow-up for various reasons.

\section{Clinical Characteristics and Selection Criteria}

All patients (Table 1) suffered from severe treatment- 
resistant pain syndromes: 8 with trigeminal neuralgia (TN) originally classified as classic neuralgia (TN1), ${ }^{2} 6$ with postherpetic TN, 5 suffering from TN with mixed constant and episodic pain and burning (TN2), ${ }^{2} 4$ with thalamic pain, 3 with secondary neuralgia/trigeminal neuropathic pain (TNP), ${ }^{2} 1$ with $\mathrm{TN}$ related to multiple sclerosis, 1 with causalgic pain, 1 with phantom pain, and 1 with facial pain of unknown etiology.

For thalamotomy, patients were selected with 1) primarily poorly treatable pain (such as thalamic pain, postherpetic TN, causalgic pain, and phantom pain), in which GKT was indicated as a last-line treatment; and 2) pain in the trigeminal region in which standard treatment had failed and/or neuralgic irritation had signs of trigeminal deafferentation pain $(\mathrm{TDP})^{2}$ (i.e., TN1 transformed into TDP after previous procedures, TN2, TNP, TDP, and $\mathrm{TN}$ related to multiple sclerosis). Twenty patients $(66 \%)$ had previously undergone some type of neurosurgical procedure (microvascular decompression [MVD], glycerol rhizotomy, balloon microcompression, Gamma Knife irradiation of the trigeminal root, and radiofrequency thermolesion) prior to GKT.

\section{Radiosurgery, Imaging, and Targeting Technique}

Radiosurgery was performed using the Leksell Gamma Knife models B, C, and Perfexion (Elekta Instruments). MRI was performed at $1.5 \mathrm{~T}$ and included T1-weighted 3D fast low-angle shot (1.3-mm slice thickness) as well as T2- and proton density-weighted sequences (2-mm slice thickness). Radiation planning was performed using GammaPlan software (Elekta Instruments). The intralaminar nuclei (centromedian [CM] and parafascicularis [Pf] nucleus) of the medial thalamus ${ }^{9,14}$ were chosen as the target (Fig. 1) for irradiation with the following coordinates: $\mathrm{X}=$ 4-6 mm lateral to wall of the third ventricle; $Y=7-8 \mathrm{~mm}$ posterior to the midpoint; and $\mathrm{Z}=2-3 \mathrm{~mm}$ above the anterior commissure-posterior commissure line contralateral to pain symptoms. The radiation itself was performed using a 4-mm collimator and a single shot with an applied maximal dose between 145 and 150 Gy (Fig. 1). MRI with contrast administration was performed 3-9 months after GKT in 8 patients.

\section{Outcome of Pain Relief}

All patients were examined neurologically, including the evaluation of pain relief as well as sensory and motor functions prior to GKT and then 3, 6, and 12 months after irradiation, and annually or biannually thereafter. For pain evaluation the intensity, frequency, and eventually change in the character of pain were considered.

Patients classified their degree of pain relief by using a percentile scale with $0 \%$ being pain free and $100 \%$ corresponding to no change. The patients were divided into 5 groups according to their perception of residual pain as follows: group I, excellent $(0 \%)$; group II, very good pain relief $(1 \%-25 \%)$, group III, good $(26 \%-50 \%)$; group IV, poor $(51 \%-75 \%)$; and group $\mathrm{V}$, very poor $(76 \%-100 \%)$. Pain relief that was classified as group I, II, or III was considered successful treatment. We also evaluated pain using the Barrow Neurological Institute (BNI) pain intensity

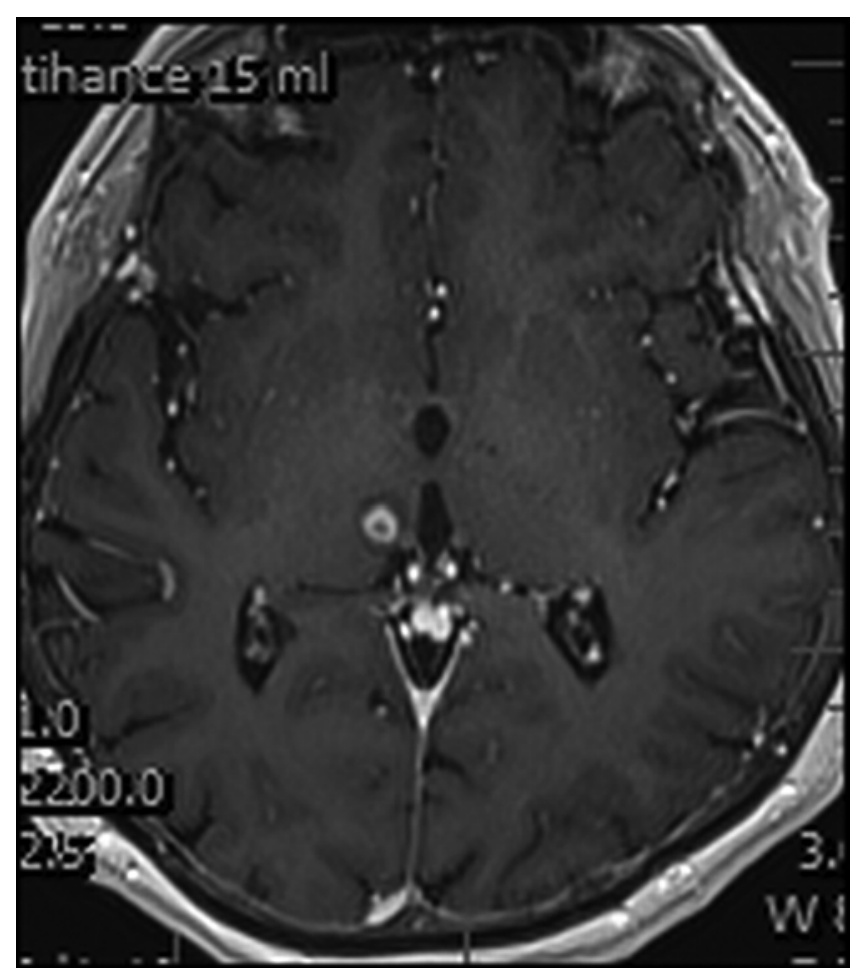

FIG. 1. Axial MR image of the GKT lesion (145 Gy) showing contrast enhancement in the medial thalamus (CM/Pf complex) 9 months after treatment. The volume of enhancement was $70 \mathrm{~mm}^{3}$, and the diameter was $6 \mathrm{~mm}$.

scale: BNI 1 = no pain, no medication; BNI $2=$ occasional pain, no medication; BNI 3 = some pain, adequately controlled with medication; BNI 4 = some pain, not adequately controlled with medication; and BNI $5=$ severe pain or no pain relief. BNI scores of 1,2 , or 3 were considered to indicate treatment success, whereas BNI scores of 4 or 5 indicated treatment failure.

\section{Results}

\section{Outcome of Pain Relief}

One patient was pain free (group I, BNI 1), 2 patients achieved a classification of very good pain relief (group II, BNI 2), 10 patients reached good pain relief (group III, BNI 3), and in 17 cases there was minimal or no pain relief (groups IV and V, BNI 4 and 5). Thus, the treatment was successful in $43.3 \%$ of patients (groups I-III, BNI 1-3) and failed in $56.7 \%$ of patients (Table 1). The interval between radiosurgery and successful pain relief ranged from 2 to 12 months (median 3 months). The duration of pain reduction was 10-72 months; in 4 patients pain relief was interrupted by recurrence (see below); the rest of the patients are still being followed or were lost to follow-up (Fig. 2).

\section{Recurrence of Pain}

Pain recurred in $4(31 \%)$ of 13 patients between 22 and 30 months after irradiation (median 24 months; Table 1). Recurrence was defined as initial excellent or very good pain response (groups I and II), later classified as poor 


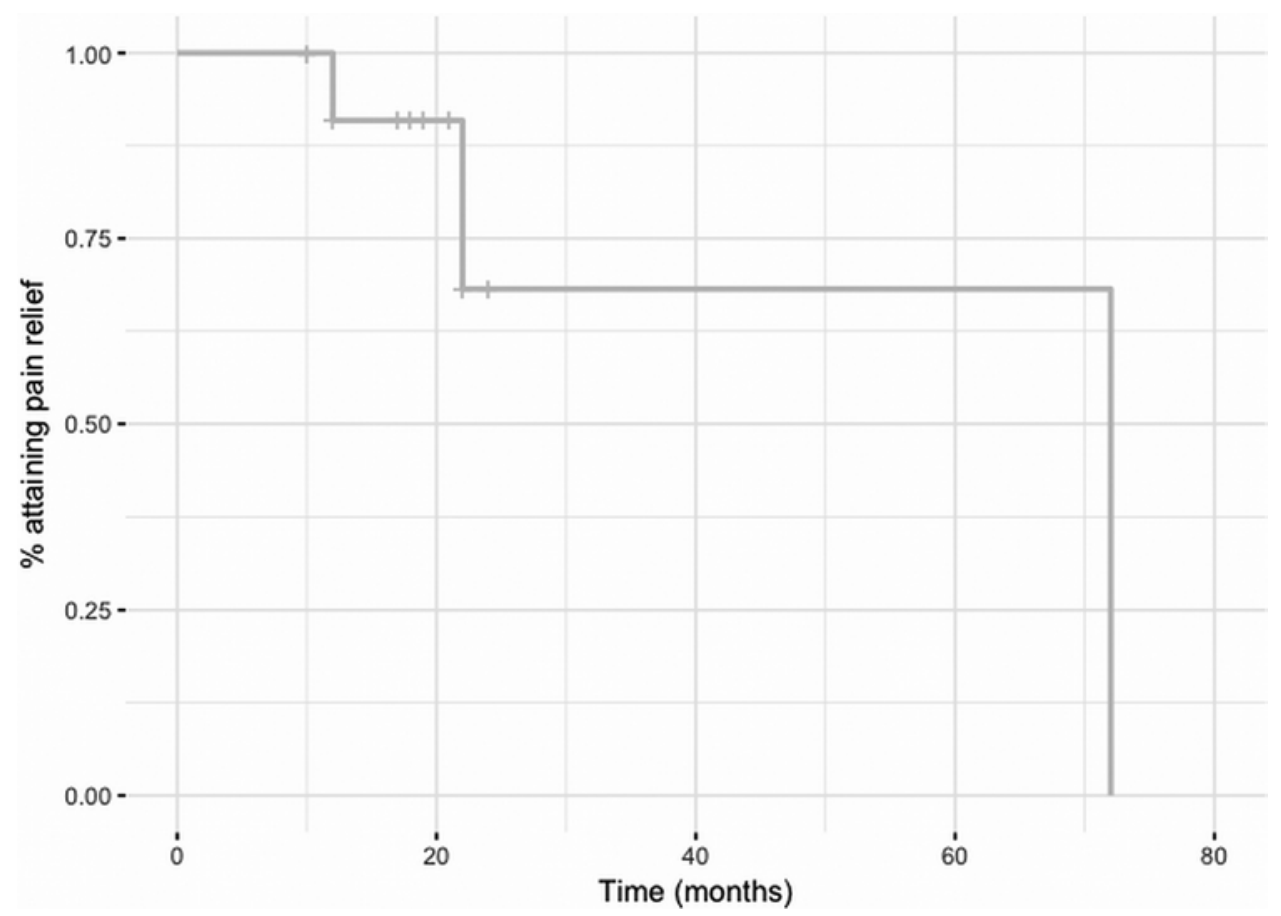

FIG. 2. Kaplan-Meier curve of the duration of pain relief in the study for patients who experienced relief.

or very poor (group IV or V), or if a patient moved from group III to group V.

\section{Adverse Effects}

We did not observe any new neurological impairment or worsening of existing neurological deficits. No worsening of pain symptoms occurred.

\section{Magnetic Resonance Imaging}

Contrast enhancement after GKT (145 Gy) was described in all patients in the medial thalamus (Fig. 1). The diameter of ovoid shape enhancement was 3-7 mm in all patients, with the exception of 1 patient in whom the enhancement was $12 \mathrm{~mm}$ in diameter. This larger volume of enhancement was not associated with clinical side effects.

\section{Discussion}

The initial overall success rate (good, very good, and excellent pain relief; BNI 1-3) was $43.3 \%$ in our patients, with only 1 patient being pain free after GKS. Our results are comparable to those of Steiner et al. ${ }^{13}$ and Young et al..$^{17}$ on medial GKT (CM/Pf complex). Steiner et al..$^{13}$ treated patients with pain due to malignancy, while Young et al. ${ }^{17}$ treated patients for various pain syndromes of nonmalignant origin. The number of treated patients in both of these studies was similar to our work. Steiner et al. ${ }^{13}$ reported good pain relief in $8(15 \%)$ cases and moderate pain relief in $18(35 \%)$ patients. Young et al. ${ }^{17}$ reported excellent or good pain relief in two-thirds of patients; however, higher doses of radiation were applied (140-180 Gy) and 1-3 isocenters were used. They described 3 postradiation complications and 1 death in relation to bilateral thalamotomy.
Further papers present the results of classic thermolesions ${ }^{7}$ and thermolesions performed by tcMRgFUS ablation, especially the work of Jeanmonod et al. ${ }^{6-8}$ in recent years. Jeanmonod et al. ${ }^{6-8}$ reported significant improvement of pain in $75 \%$ of cases (from 12 patients), and in the larger group of 96 patients they reported pain relief (greater than $50 \%$ ) in $53 \%$ of patients. However, they targeted a different region of the medial thalamus, the posterior part of the centrolateral thalamic nucleus (CLp). They additionally applied a second lesion in the CLp ipsilateral to the unilateral pain in 28 patients. A second lesion (bilateral procedure) improved pain relief after the first lesion.

The overall success rate of pain relief in $43 \%$ of patients after $\mathrm{CM} / \mathrm{Pf}$ GKT is not particularly remarkable. We must consider, however, that these patients suffered from intractable pain, in which previous treatments failed. Importantly, we did not observe any treatment complications. Increasing the lesion by applying a higher radiation dose could increase the success rate, but doses above 150 Gy may already cause unpredictably large ${ }^{16}$ areas of radionecrosis and thus undesirable clinical effects. A possible way to improve the efficiency of GKT is to change the radiation target, i.e., to move the target from the $\mathrm{CM}$ / Pf complex to the CLp region according to the methodology of Jeanmonod and Morel. ${ }^{7}$ Another option would be to consider bilateral GKT lesions even in unilateral pain syndromes. ${ }^{7}$ Medial GKT can by beneficial for some patients with intractable pain, especially those with relatively poor clinical status. Further prospective investigation would be beneficial.

\section{Conclusions}

Medial GKT is a minimally invasive technique for the 
treatment of intractable pain, even in those patients for whom other neurosurgical procedures have failed. The relatively low success rate of GKS is balanced by virtually no clinical side effects. GKT may be beneficial for some patients and suitable for those with overall poor clinical status.

\section{Acknowledgments}

This study was supported by $\mathrm{MH} \mathrm{CZ}-\mathrm{DRO}$ (grants $\mathrm{NHH}$, 00023884).

\section{References}

1. Cetas JS, Saedi T, Burchiel KJ: Destructive procedures for the treatment of nonmalignant pain: a structured literature review. J Neurosurg 109:389-404, 2008

2. Eller JL, Raslan AM, Burchiel KJ: Trigeminal neuralgia: definition and classification. Neurosurg Focus 18(5):E3, 2005

3. Fairman D: Unilateral thalamic tractotomy for the relief of bilateral pain in malignant tumors. Confin Neurol 29:146152,1967

4. Gerhart KD, Yezierski RP, Fang ZR, Willis WD: Inhibition of primate spinothalamic tract neurons by stimulation in ventral posterior lateral (VPLc) thalamic nucleus: possible mechanisms. J Neurophysiol 49:406-423, 1983

5. Head H, Holmes G: Sensory disturbances from cerebral lesions. Brain 34:102-254, 1911

6. Jeanmonod D, Magnin M, Morel A: Thalamus and neurogenic pain: physiological, anatomical and clinical data. Neuroreport 4:475-478, 1993

7. Jeanmonod D, Morel A: The central lateral thalamotomy for neuropathic pain, in Lozano AM, Gildenberg PL, Tasker RR (eds): Textbook of Stereotactic and Functional Neurosurgery, ed 2. Berlin: Springer, 2009, pp 2081-2096

8. Jeanmonod D, Werner B, Morel A, Michels L, Zadicario E, Schiff G, et al: Transcranial magnetic resonance imagingguided focused ultrasound: noninvasive central lateral thalamotomy for chronic neuropathic pain. Neurosurg Focus 32(1):E1, 2012

9. Morel A: Stereotactic Atlas of the Human Thalamus and Basal Ganglia. New York: Informa Healthcare, 2007

10. Moser D, Zadicario E, Schiff G, Jeanmonod D: Measurement of targeting accuracy in focused ultrasound functional neurosurgery. Neurosurg Focus 32(1):E2, 2012

11. Niranjan A, Raju SS, Kooshkabadi A, Monaco E III, Flickinger JC, Lunsford LD: Stereotactic radiosurgery for essential tremor: Retrospective analysis of a 19-year experience. Mov Disord 32:769-777, 2017
12. Richardson DE: Thalamotomy for intractable pain. Confin Neurol 29:139-145, 1967

13. Steiner L, Forster D, Leksell L, Meyerson BA, Boëthius J: Gammathalamotomy in intractable pain. Acta Neurochir (Wien) 52:173-184, 1980

14. Urgosik D, Liscak R: Medial gamma-thalamotomy for intractable pain. Stereotact Funct Neurosurg 94 (Suppl 1):35, 2016 (Abstract)

15. Witjas T, Carron R, Boutin E, Eusebio A, Azulay JP, Régis $\mathrm{J}$ : Essential tremor: Update of therapeutic strategies (medical treatment and gamma knife thalamotomy). Rev Neurol (Paris) 172:408-415, 2016

16. Young RF, Bach FW, Van Norman AS, Yaksh TL: Release of beta-endorphin and methionine-enkephalin into cerebrospinal fluid during deep brain stimulation for chronic pain. Effects of stimulation locus and site of sampling. J Neurosurg 79:816-825, 1993

17. Young RF, Vermeulen SS, Grimm P, Posewitz AE, Jacques DB, Rand RW, et al: Gamma Knife thalamotomy for the treatment of persistent pain. Stereotact Funct Neurosurg 64 (Suppl 1):172-181, 1995

\section{Disclosures}

The authors report no conflict of interest concerning the materials or methods used in this study or the findings specified in this paper.

\section{Author Contributions}

Conception and design: Urgosik. Acquisition of data: Urgosik. Analysis and interpretation of data: both authors. Drafting the article: Urgosik. Critically revising the article: Liscak. Reviewed submitted version of manuscript: both authors. Approved the final version of the manuscript on behalf of both authors: Urgosik. Administrative/technical/material support: Liscak.

\section{Supplemental Information}

Previous Presentations

Portions of the results of this paper were presented at the 22nd Congress of the European Society for Stereotactic and Functional Neurosurgery in Madrid, Spain, September 28-October 1, 2016, and at the 19th International Leksell Gamma Knife Society Meeting, in Dubai, United Arab Emirates, March 4-8, 2018.

\section{Correspondence}

Dusan Urgosik: Na Homolce Hospital, Prague, Czech Republic. dusan.urgosik@homolka.cz. 